\title{
PENGARUH PENDIDIKAN KESEHATAN TENTANG IVA TERHADAP PENGETAHUAN WUS MELALUI MEDIA LEAFLET BERKALENDER DI WILAYAH KERJA PUSKESMAS LUBUK BUAYA PADANG TAHUN 2018
}

\author{
${ }^{1}$ Lindawati, ${ }^{2}$ Meta Rikandi \\ ${ }^{1}$ Akbid Alifah Padang, \\ Email*: inno s@yahoo.co.id \\ ${ }^{2}$ STIKes Alifah Padang ${ }^{2}$ \\ Email : meta.rikandi@gmail.com
}

\begin{abstract}
ABSTRAK
Tingginya kasus kematian disebabkan oleh kanker serviks pada wanita di Indonesia terjadi karena umumnya kanker tersebut baru diketahui setelah memasuki stadium lanjut. Data dari Puskesmas Lubuk Buaya didapatkan yang melakukan pemeriksaan IVA sebanyak 50 orang $(0,4 \%)$ dari 14.199 sasaran. Penelitian ini bertujuan untuk mengetahui Pengaruh Pendidikan Kesehatan Tentang IVA Terhadap Pengetahuan WUS Melalui Media Leaflet Berkalender dalam upaya deteksi dini kanker serviks di Puskesmas Lubuk Buaya Pdang Tahun 2018. Populasi berjumlah 30 orang, analisis data yang digunakan yaitu univariat dan bivariat. Hasil Penelitian pada kelompok kontrol didapatkan pengetahuan responden sebelum diberikan perlakuan 53\% menjadi $73 \%$ sedangkan pada kelompok intervensi didapatkan pengetahuan responden $67 \%$ menjadi $87 \%$. Hasil uji statistik terdapat perbedaan secara sifnifikan antara pengetahuan wanita usia subur sebelum dan setelah diberikan pendidikan kesehatan dengan nilai $\mathrm{p}=0,0001(\alpha=0,05)$.Pihak Puskesmas Lubuk Buaya Padang serta petugas setempat harus lebih memperhatikan keberhasilan program pemeriksaan dini kanker serviks metode IVA dengan adanya pembentukkan kader pada setiap kelurahan sehingga pemberian informasi dapat diberikan secara menyuluruh.
\end{abstract}

Kata Kunci : Pendidikan kesehatan, Pengetahuan

\begin{abstract}
The high number of deaths caused by cervical cancer in women in Indonesia occurs because the cancer is generally only known after entering an advanced stage. Data from Puskesmas Lubuk Buaya were obtained that performed IVA examination as many as 50 people $(0,4 \%)$ from 14,199 target. This study aims to determine the influence of Health Education About IVA on WUS Knowledge Through Media Leaflet Berkalender in the early detection of cervical cancer in Puskesmas Lubuk Buaya Pdang 2018. Population amounted to 30 people, data analysis used is univariate and bivariate. The result of the research in the control group was got the knowledge of the respondents before the treatment was given $53 \%$ to $73 \%$ while in the intervention group got $67 \%$ respondents knowledge to $87 \%$. The result of statistical test shows that there is a significant difference between the knowledge of women of reproductive age before and after being given health education with $p$ value $=0.0001(\alpha=0,05)$. The Puskesmas Lubuk Buaya Padang and local officers should pay more attention to the success of early cervical examination program IVA method with the formation of cadres in each kelurahan so that the provision of information can be given thoroughly.
\end{abstract}

Keywords: Health Education, Knowledge, 


\section{PENDAHULUAN}

Kanker merupakan salah satu penyakit dengan angka kematian yang tinggi. Kasus kanker di dunia setiap tahun terus meningkat. Pada tahun 2000, kanker telah didiagnosis pada 10 juta orang dan menyebabkan kematian sekitar 6,2 juta diseluruh dunia, atau terjadi peningkatan sekitar 22\% sejak tahun 1990. Kanker menjadi penyebab kematian $10 \%$ dari morbiditas total di seluruh dunia dan berada pada urutan kedua setelah penyakit kardiovaskuler serta penyebab utama kematian di negara maju. Hingga saat ini jenis kanker penyebab kematian wanita terbanyak terutama di negara berkembang adalah kanker serviks (Ariani, 2015).

Keputusan Menteri Kesehatan Republik Indonesia nomor 796/MENKES/SK/VII/2010 tentang pedoman teknis secara nasional dan intervensi yang memadai melalui pencegahan primer, sekunder, dan tersier. Keputusan ini berkaitan dengan keikutsertaan peran pemerintah dalam melakukan pencegahan penyakit kanker serviks yang mematikan. Pencegahan ini termasuk kedalam pencegahan primer yaitu dengan mengadakan pemeriksaan Skrinning IVA dan Pap smear dengan tujuan untuk mendeteksi dini penyakit kanker serviks agar dapat dilakukan pencegahan dan penanganan lebih awal (Kebijakan Kesehatan Indonesia, 2011).

IVA (Inspeksi Visual Asam Asetat) adalah suatu metode untuk mendeteksi secara dini lesi pra kanker dengan menggunakan kapas lidi yang telah dicelupkan ke dalam asam cuka atau asam asetat dengan konsentrasi 3-5\% yang nantinya akan dioleskan pada vagina tepatnya pada daerah portio dengan teknik pengolesan searah jarum jam.

Data Dinas Kesehatan Kota Padang tahun 2014 mengatakan dari 22 Puskesmas yang ada di Kota Padang, Puskemas Lubuk Buaya merupakan salah satu Puskesmas yang melakukan pemeriksan dini kanker serviks dengan metode IVA. Data dari Puskesmas Lubuk Buaya cakupan pemeriksaan IVA belum maksimal pada tahun 2014 yang melakukan pemeriksaan IVA sebanyak 50 orang $(0,4 \%)$ dari 14.199 sasaran (Profil Kesehatan Kota Padang, 2014).

Berdasarkan survey awal yang telah dilakukan pada 10 orang Wanita Usia Subur (WUS) di Wilayah Kerja Puskesmas Lubuk Buaya Padang didapatkan hasil bahwa 4 diantaranya tidak mengetahui dan tidak pernah terpapar informasi mengenai pemeriksaan dini kanker serviks dengan metode IVA.

Berdasarkan data diatas maka peneliti telah melakukan penelitian tentang "Pengaruh Pendidikan Kesehatan Tentang IVA Terhadap Pengetahuan WUS Melalui Media Leaflet Berkalender dalam upaya deteksi dini kanker serviks di Puskesmas Lubuk Buaya Pdang Tahun 2018”.

\section{METODE PENELITIAN}

Jenis penelitian ini menggunakan pendekatan kuantitatif dengan desain quasi eksperimen dengan pendekatan pre-post test design dimana memberikan pre test (pengamatan awal) terlebih dahulu sebelum diberikan intervensi, setelah itu diberikan intervensi, kemudian dilakukan post test (pengamatan terakhir).. Sampel dalam penelitian ini adalah Wanita Pasangan Usia Subur di Wilayah Kerja Puskesmas Lubuk Buaya Padang tahun 2018 sebanyak 30 orang.

\section{HASIL DAN PEMBAHASAN}

\section{a. Analisis Univariat}

Tabel 1 Pengetahuan Wanita Usia Subur Sebelum dan Sesudah diberikan Pendidikan Kesehatan pada Kelompok Kontrol 


\begin{tabular}{ccccc}
\hline Pengeta & \multicolumn{2}{c}{ Pre test } & \multicolumn{2}{c}{ Post test } \\
\cline { 2 - 5 } huan & $\boldsymbol{f}$ & $\boldsymbol{\%}$ & $\boldsymbol{f}$ & $\boldsymbol{\%}$ \\
\hline Tinggi & 8 & 53 & 11 & 73 \\
\hline Rendah & 7 & 47 & 4 & 27 \\
\hline
\end{tabular}

Pada tabel 1 didapatkan terjadi peningkatan pengetahuan wanita usia subur sebelum diberikan pendidikan kesehatan 8 orang (53\%) menjadi 11 orang $(73 \%)$ setelah diberikan pendidikan kesehatan.

Tabel 2 Pengetahuan Wanita Usia Subur Sebelum dan Sesudah diberikan Pendidikan Kesehatan pada Kelompok intervensi

\begin{tabular}{lcccc}
\hline Penget & \multicolumn{2}{c}{ Pre test } & \multicolumn{2}{c}{ Post test } \\
\cline { 2 - 5 } ahuan & $\boldsymbol{f}$ & $\boldsymbol{\%}$ & $\boldsymbol{f}$ & $\boldsymbol{\%}$ \\
\hline Tinggi & 10 & 67 & 13 & 87 \\
\hline Rendah & 5 & 33 & 2 & 13 \\
\hline
\end{tabular}

Pada tabel 2 didapatkan terjadi peningkatan pengetahuan wanita usia subur sebelum diberikan pendidikan kesehatan 10 orang $(67 \%)$ menjadi 13 orang ( $87 \%)$ setelah diberikan pendidikan kesehatan.

\section{b. Analisis Bivariat}

Tabel 3. Perbedaan Pengetahuan Wanita Usia Subur Sebelum dan Sesudah dilakukan Pendidikan Kesehatan

\begin{tabular}{lccc}
\hline $\begin{array}{l}\text { Pengetahu } \\
\text { an }\end{array}$ & Mean & SD & p value \\
& & & \\
\hline Intervensi & 5,43 & 3.92 & 0,0001 \\
\hline kontrol & 4,12 & 2,49 & \\
\hline
\end{tabular}

Pada tabel 3 menunjukkan terdapat perbedaan rerata peningkatan pengetahuan antara kelompok intervensi dan kontrol tentang IVA, pada kelompok intervensi dengan mean 5,43 dan kelompok kontrol mean 4,14. Berdasarkan data diatas secara statistik terdapat perbedaan secara sifnifikan antara pengetahuan wanita usia subur sebelum dan setelah diberikan pendidikan kesehatan dengan nilai $\mathrm{p}=$ $0,0001(\alpha=0,05)$.

\section{PEMBAHASAN}

\section{Pengaruh Pendidikan Kesehatan terhadap Pengetahuan}

Pada penelitian ini, kelompok kontrol mendapat intervensi ceramah dengan materi kanker serviks serta cara deteksi dini yang disampaikan dengan cara berdiri didepan audien tanpa ada sesi tanya jawab. Nilai tingkat pengetahuan WUS kelompok kontrol sebesar 4,12. Kelompok intervensi mendapat intervensi pendidikan dengan ceramah melalui leaflet yang dibagikan satu persatu dan dapat dibawa pulang kerumah. Leaflet berisi tentang materi serupa dengan ceramah dan dikombinasikan dengan berbagai gambar yang mendukung.

Peneliti menemukan peningkatan skor pengetahuan pada kelompok intervensi sebesar 5,43. Sehingga ada perbedaan pengaruh pendidikan kesehatan dengan metode ceramah + leaflet dan metode ceramah terhadap tingkat pengetahuan WUS tentang IVA dalam upaya deteksi dini kanker serviks $(p=0,000)$. Terdapat hubungan tingkat pengetahuan WUS dengan pemeriksaan IVA. Jhon (2011) telah melakukan penelitian di Songea, Rumuva bahwa pengetahuan wanita yang berusia diatas 18 tahun mengenai screening kanker serviks sangatlah rendah dan hal ini menyebabkan partisipasi untuk melakukan skrining juga rendah. Nurana (2008) juga menyimpulkan rendahnya pengetahuan perempuan mengenai kanker serviks membuat rendahnya keinginan perempuan untuk melakukan deteksi dini. Hal ini dikarenakan perempuan Indonesia masih awam dengan kanker serviks.

Pendidikan kesehatan pada kelompok eksperimen memungkinkan WUS 
menggunakan lebih dari 1 indera. Nilai peningkatan tingkat pengetahuan dan sikap pada kelompok kontrol meningkat lebih kecil daripada kelompok eksperimen. Hal ini disebabkan karena pada kelompok kontrol materi yang disampaikan pada saat ceramah tidak dapat diulang kembali pada saat WUS dirumah atau selesai mendengarkan. Dibandingkan dengan kelompok eksperimen yang dapat mengulang kembali materi pendidikan kesehatan melalui leaflet berkalender yang telah dibagikan.

Hal tersebut sesuai dengan teori kerucut Edgar Dale yang menyusun fungsi alat peraga berdasarkan prinsip pengetahuan pada manusia diterima melalui panca indera dan dipengaruhi oleh intesitas alat peraga yang berbeda.Semakin banyak indera yang digunakan, semakin banyak dan jelas pengetahuan yang diperoleh.Media pendidikan kesehatan diperlukan untuk menumbuhkan minat belajar, membantu sasaran untuk mengerti lebih baik, mengingat dengan baik dan membantu mengatasi kesulitan bahasa. Media yang digunakan tersebut dapat menunjang pemberian materi yang disampaikan melalui ceramah. Penggunaan media leaflet berkalender akan menarik dan memberikan motivasi untuk mendapatkan informasi WUS. Hambatan WUS dalam menggunakan pelayanan kesehatan reproduksi khususnya berhubungan dengan Kanker Serviks adalah keadaan ekonomi, perasaan malu, takut pada proses pemeriksaan, takut akan rasa sakit yang ditimbulkan setelah pemeriksaan, fasilitas kurang lengkap serta informasi

dan pengetahuan WUS yang kurang.

Pendidikan kesehatan merupakan suatu proses yang mencakup dimensi dan kegiatankegiatan intelektual, psikologi, dan sosial yang diperlukan untuk meningkatkan kemamapuan individu dalam mengambil keputusan secara sadar dan yang mempengaruhi kesejahteraan diri, keluarga dan masyarakat.

Proses ini didasarkan pada prinsip-prinsip ilmu pengetahuan yang memberi kemudahan untuk belajar dan merubah perilaku, baik bagi tenaga kesehatan maupun bagi pemakai jasa pelayanan. Batasan pendidikan kesehatan pada dasarnya merupakan upaya-upaya terencana untuk mengubah perilaku individu, kelompok, keluarga, dan masyarakat. Hal tersebut juga menunjukkan bahwa pendidikan kesehatan membutuhkan pemahaman yang mendalam, karena melibatkan berbagai istilah atau konsep seperti perubahan dan proses pendidikan (Maulana, 2009).Semakin berkembangnya teknologi saat ini diharapkan akan dapat membantu atau menunjang pemberian pendidikan kesehatan agar mendapatkan hasil yang optimal untuk meningkatkan derajat kesehatan masyarakat.

Hasil analisis terhadap jawaban kuesioner responden pada saat pre-test dan post-test kedua kelompok didapatkan soal yang masih belum benar pada saat post-test. Soal pengetahuan tentang deteksi dini kanker serviks dilakukan minimal 2 kali masih banyak yang menjawab salah karena pada leaflet berkalender dan ceramah lebih spesifik menyebutkan deteksi dini IVA atau Pap-smear dilakukan minimal 2 tahun sekali bagi wanita yang berusia diatas 35 tahun yang hasil IVA atau Pap-smear sebelumnya negatif. Sedangkan pada pertanyaan sikap, tentang perlunya wanita yang telah menopause melakukan pemeriksaan IVA, WUS masih beranggapan bahwa wanita yang telah menopause tidak perlu melakukan pemeriksaan IVA. Hal ini karena wanita yang menopause sudah tidak lagi mengalami menstruasi sehingga masa reproduksi mereka terhenti, sedangkan pada leaflet berkalender dan ceramah 
belum dijelaskan secara spesifik bahwa wanita yang telah menopause juga dianjurkan untuk melakukan pemeriksaan IVA dan Pap-smear karena wanita yang menopause juga merupakan faktor risiko terjadinya kanker serviks. Pada penelitian ini tidak sampai diteliti hingga faktor-faktor internal maupun eksternal yang berpengaruh pada perilaku WUS untuk melakukan pemeriksaan IVA.

Keuntungan penyuluhan dengan metode ceramah adalah mudah digunakan, dapat mempengaruhi pendapat dan merangsang pikiran dengan kritis. Efektifitas penggunaan ceramah dapat ditingkatkan dengan dikombinasikan dengan berbagai macam media pendidikan kesehatan.Pendidikan kesehatan pada kelompok eksperimen memungkinkan WUS menggunakan lebih dari 1 indera. Nilai peningkatan tingkat pengetahuan dan sikap pada kelompok kontrol meningkat lebih kecil daripada kelompok eksperimen. Hal ini disebabkan karena pada kelompok kontrol materi yang disampaikan pada saat ceramah tidak dapat diulang kembali pada saat WUS dirumah atau selesai mendengarkan. Dibandingkan dengan kelompok eksperimen yang dapat mengulang kembali materi pendidikan kesehatan melalui leaflet berkalender yang telah dibagikan. Hal tersebut sesuai dengan teori kerucut Edgar Dale yang menyusun fungsi alat peraga berdasarkan prinsip pengetahuan pada manusia diterima melalui panca indera dan dipengaruhi oleh intesitas alat peraga yang berbeda.Semakin banyak indera yang digunakan, semakin banyak dan jelas pengetahuan yang diperoleh.

Media pendidikan kesehatan diperlukan untuk menumbuhkan minat belajar, membantu sasaran untuk mengerti lebih baik, mengingat dengan baik dan membantu mengatasi kesulitan bahasa.Media yang digunakan tersebut dapat menunjang pemberian materi yang disampaikan melalui ceramah. Penggunaan media leaflet berkalender akan menarik dan memberikan motivasi untuk mendapatkan informasi WUS. Hambatan WUS dalam menggunakan pelayanan kesehatan reproduksi khususnya berhubungan dengan Kanker Serviks adalah keadaan ekonomi, perasaan malu, takut pada proses pemeriksaan, takut akan rasa sakit yang ditimbulkan setelah pemeriksaan, fasilitas kurang lengkap serta informasi dan pengetahuan WUS yang kurang.

\section{UCAPAN TERIMA KASIH}

Penulis mengucapkan terima kasih sedalam-dalamnya kepada Yayasan Alifah Nur Ikhlas Padang yang telah memberikan kesempatan untuk melaksanakan penelitian serta memberikan bantuan dana untuk penelitian ini. Ketua STIKes beserta rekan-rekan, Dinas Kesehatan dan Kepala Puskesmas beserta jajaran yang telah memberikan kesempatan untuk melakukan penelitian di Wilayah Puskesmas Lubuk Buaya Padang.

\section{DAFTAR PUSTAKA}

Diananda, Rama. 2008. Mengenal Seluk Beluk Kanker, Yogyakarta : Kata Hati

Emilia, 2010. Pengertian Kanker, http://www.kanker.com, diakses pada tanggal 26 Febuari 2016

Firzanah, Fia. 2012. Hubungan Motivasi Suami dengan Sikap WUS pada Deteksi Dini Kanker Serviks dengan Cara IVA di Puskesmas Gambiran Kecamatan Mojoagung Kabupaten Jombang. Diakses pada tanggal 23 Maret 2016. 
Hanggayasti, 2012. Tingkat Pengetahuan Ibu Wanita Usia Subur tentang Pemeriksaan Inveksi Asam Asetat. Diakses pada tanggal 19 Maret 2016.

Hartati, 2010. Waspadai 4 Kanker Ganas Pembunuh Wanita, Yogyakarta : C.V ANDI

Indrayani, Diyan. 2009. Hubungan Antara Pengetahuan Ibu Tentang Kanker Serviks dan Perilaku Deteksi Dini Kanker Serviks di Kelurahan Pacar Kembang Kota Surabaya. Diakses pada tanggal 03 Maret 2016

Kurniawati, Indah. 2015. Pengaruh Pengetahuan, Motivasi, dan Dukungan Suami Terhadap Perilaku Pemeriksaan IVA pada Wanita Usia Subur di Puskesmas Kedungrejo. Diakses pada tanggal 03 Maret 2016.

Kurniawati, Widyastuti, Faridah Aini dan Sugeng Maryanto. 2013. FaktorFaktor yang Berhubungan dengan Perilaku WUS dalam Deteksi Dini Kanker Serviks dengan Metode IVA di Wilayah Kerja Puskesmas Kretek Bantul Yogyakarta. Diakses pada tanggal 19 Maret 2016.

Lindayati. 2011. Hubungan Tingkat Pengetahuan dan Sikap Wanita Pasangan Usia Subur dengan Tindakan Pencegahan Kanker Serviks di Wilayah Kerja Puskesmas Air Tawar Padang Utara. Diakses pada tanggal 23 Maret 2016.

Mardani, 2013. Hubungan Tingkat Pengetahuan dan Sikap Wanita Usia Subur (WUS) dengan Pemeriksaan Inspeksi Visual Asam Asetat di Puskesmas Bulelang. Diakses pada tanggal 19 Maret 2016.
Martini, Ni Ketut. 2013. Hubungan Karakteristik Pengetahuan dan Sikap Wanita Pasangan Usia Subur dengan Tindakan Pemeriksaan Dini Kanker Serviks di Puskesmas Sukawati II Denpasar. Diakses pada tanggal 03 Maret 2016.

Mubarak, 2010. Ilmu Keperawatan Komunitas Konsep dan Aplikasi, Jakarta : EGC

Nasihah, Mimatun dan Sifia Lorna B. 2013. Hubungan Antara Pengetahuan dan Pendidikan dengan Pelaksana Deteksi Dini Kanker Serviks Melalui IVA. Diakses pada tanggal 03 Maret 2016.

Notoatmodjo, 2008. Perilaku dan Promosi Kesehatan, Jakarta : Rineka Cipta , 2011. Perilaku dan Promosi Kesehatan, Jakarta : Rineka Cipta

Nurhasanah, C. 2008. Pengaruh Karakteristik dan Perilaku Pasangan Usia Subur (PUS) Terhadap Pemeriksaan Pap Smear di RSUZA Banda Aceh. Diakses pada tanggal 03 Maret 2016.

Nurtini, Ni Made. 2012. Hubungan Pengetahuan dan Sikap Wanita Usia Subur dengan Pencegahan kanker serviks Metode IVA. Diakses pada tanggal 19 Maret 2016.

Prabandari, 2011. Beberapa Faktor yang Mempengaruhi Minat WUS (Wanita Usia Subur) Dalam Pemeriksaan IVA. Diakses pada tanggal 03 Maret 2016.

Pudiastuti, Ratna Dewi. 2014. Kebidanan Komunitas, Jakarta : EGC

Rasjidi, 2008. Waspada Kanker Pada Pria \& Wanita, Yogyakarta : Siklus 
, 2010. Waspada Kanker Pada Pria \& Wanita, Yogyakarta : Siklus

Rokhmawati, 2011. Inspeksi Visual Asam Asetat, Jakarta

Rukiah, dkk. 2014. Asuhan Kebidanan Ibu Hamil. Jakarta : CV. Trans Media

Safaah, Nurus. 2011. Faktor-Faktor yang Berhubungan dengan Motivasi Wanita Usia Subur yang Melakukan Pemeriksaan IVA dalam Upaya Deteksi Dini Kanker Serviks. Diakses pada tanggal 19 Maret 2016.

Samadi, Heru Priyanto. 2010. Yes,I Know Everything About Kanker Serviks. Solo: Metagraf Creative Imprint Of Tiga Serangkai

Saraswati, 2011. Pengaruh Promosi Kesehatan terhadap Pengetahuan tentang Kanker Serviks dan Partisipasi Wanita dalam Deteksi Dini Kanker Serviks. Diakses pada tanggal 23 Maret 2016.

Saraswati, Karisma Lia. 2011. Pengaruh Promosi Kesehatan Terhadap Pengetahuan dan Partisipasi WUS dalam Deteksi Dini Kanker Serviks Mojosongo RW/22 Surakarta. Diakses pada tanggal 23 Maret 2016.

Setiadi. 2007. Konsep dan Penulisan Riset Keperawatan, Surabaya : EGC

Setiati, Eni. 2009. Waspadai 4 Kanker Ganas Pembunuh Wanita. CV Andi Offset Cetakan Pertama: Yogyakarta

Sholihah, Anin Nur dan Etik Sulistyorini. 2015. Hubungan Antara Sikap Pencegahan Kanker Serviks dengan Minat Deteksi Dini Kanker Serviks Menggunakan Inspeksi Visual Asam Asetat pada WUS di RW IV Desa
Congkol Mojoloban Sukoharjo. Diakses pada tanggal 19 Maret 2016.

Sumastri, Heni dan Nurhidayah. 2013. Hubungan Antara Perilaku Ibu dengan Deteksi Dini Ca Cerviks Menggunakan IVA Test di Puskesmas Basuki Rahmat Palembang. Diakses pada tanggal 23 Maret 2016.

Suprijanto, H. 2008. Pendidikan Orang Dewasa. Bumi Aksara : Jakarta

Utami, Nungky Marcellia. 2013. Hubungan Tingkat Pengetahuan dengan Perilaku Deteksi Dini Kanker Serviks Pada Pasangan Usia Subur di Wilayah Kerja Puskesmas Sangkrah. Diakses pada tanggal 23 Maret 2016.

Wahyuni, Sri. 2013. Faktor-Faktor yang Mempengaruhi Perilaku Deteksi Dini Kanker Serviks di Kecamatan Ngampel Kabupaten Kendal Jawa Tengah. Diakses pada tanggal 23 Maret 2016.

Wawan, 2011. Teori dan Pengukuran Pengetahuan, Sikap dan Perilaku Manusia, Yogyakarta : Nuha Medika

Wulandari, Fitria Eka. 2013. Hubungan Pengetahuan Wanita Usia Subur tentang IVA Test dengan Perilaku IVA Test di Desa Gunting Kecamatan Wonosari Klaten. Diakses pada tanggal 19 Maret 2016.

Yuliawati. 2012. Faktor-Faktor yang Berhubungan dengan Perilaku WUS dalam Deteksi Dini Leher Rahim Metode IVA di Puskesmas Perembun Kabupaten Kebumen. Diakses pada tanggal 03 Maret 2016.

Yutiasari, Beutifina. 2015. Faktor-Faktor yang Berhubungan dengan Motivasi 
Volume 2 Nomor 2 P-ISSN : 2597-8594

Pasangan Wanita Usia Subur dalam Mengikuti Upaya Pencegahan Ca Cerviks Melalui Metode IVA di UPTD Puskesmas Sangkrah. Diakses pada tanggal 19 Maret 2016. 